\title{
Hypotensive response after water-walking and land-walking exercise sessions in healthy trained and untrained women
}

This article was published in the following Dove Press journal:

International Journal of General Medicine

5 August 20II

Number of times this article has been viewed

\author{
Daniel Rodriguez' \\ Valter Silva ${ }^{2}$ \\ Jonato Prestes ${ }^{3}$ \\ Roberta Luksevicius Rica ${ }^{4}$ \\ Andrey Jorge Serra ${ }^{5}$ \\ Danilo Sales Bocalini ${ }^{6}$ \\ Francisco Luciano Pontes \\ Junior ${ }^{7}$
}

'São Judas Tadeu University, São Paulo, SP, Brazil; ${ }^{2}$ College of Physical Education of Sorocaba, Sorocaba, SP, Brazil; ${ }^{3}$ Graduation Program in Physical Education, Catholic University of Brasilia, Brasilia-DF, Brazil; ${ }^{4}$ Department of Physical Education, Arbos College, São Bernardo do Campo, SP, Brazil; ${ }^{5}$ Department of Physical Education and Laboratory of Rehabilitation Science, Nove de Julho University, São Paulo, SP, Brazil; ' ${ }^{\text {Department of }}$ Medicine, Federal University of São Paulo - Escola Paulista de Medicina, São Paulo, SP, Brazil; ${ }^{7}$ School of Arts, Sciences and Humanities, University of São Paulo, São Paulo, SP, Brazil

Correspondence: Danilo Sales Bocalini Rua General Chagas Santos 392,

Saúde, São Paulo, SP, 04I46-050, Brazil

Tel +55 II 5587 I 700

$\mathrm{Fax}+55$ I। 5587 I700

Email bocalini@fcr.epm.br
Background: The aim of this study was to compare post-exercise hypotension after acute sessions of water-walking and land-walking in healthy trained and untrained women.

Methods: Twenty-three untrained $(n=12)$ and trained $(n=11)$ normotensive women performed two walking sessions in water and on land at $40 \%$ of peak $\mathrm{VO}_{2}$ for 45 minutes. Systolic and diastolic blood pressure and mean arterial pressure were measured 15, 30, 45, and 60 minutes after the exercise sessions.

Results: No differences were found between the groups for age and anthropometric parameters, but peak $\mathrm{VO}_{2}$ for the trained women $(45 \pm 8 \mathrm{~mL} / \mathrm{kg} /$ minute) was higher than for the untrained women ( $31 \pm 3 \mathrm{~mL} / \mathrm{kg} /$ minute). No differences were found between the groups with regard to systolic and diastolic blood pressure and mean arterial pressure after water immersion. The heart rate in the trained group $(62 \pm 3$ beats per minute $[\mathrm{bpm}])$ was significantly lower $(P<0.05)$ than in the untrained group (72 $\pm 4 \mathrm{bpm})$ on land, and after water immersion, this difference disappeared ( $58 \pm 5 \mathrm{bpm}$ in the trained women and $66 \pm 5 \mathrm{bpm}$ in the untrained women). Sixty minutes after water-walking, systolic blood pressure (108 $\pm 8 \mathrm{mmHg}$ vs $97 \pm 3 \mathrm{mmHg}$ ), diastolic blood pressure $(69 \pm 5 \mathrm{mmHg}$ vs $62 \pm 5 \mathrm{mmHg}$ ), and mean arterial pressure ( $82 \pm 6 \mathrm{mmHg}$ vs $74 \pm 4 \mathrm{mmHg}$ ) decreased significantly with rest in the untrained group, and no differences were found after land-walking. In the trained group, significant $(P<0.05)$ differences were found only for systolic blood pressure $(110 \pm 9 \mathrm{mmHg}$ vs $100 \pm 9 \mathrm{mmHg})$ after 60 minutes of waterwalking; decreases in systolic blood pressure were found after 45 minutes $(99 \pm 7 \mathrm{mmHg}$ ) and 60 minutes $(99 \pm 6 \mathrm{mmHg})$ compared with rest $(107 \pm 5 \mathrm{mmHg})$ after land-walking.

Conclusion: Single water-walking and land-walking sessions induced important hypotension following exercise. Additionally, walking performed in chest-deep water has a better effect on exercise-induced hypotension in untrained healthy women than walking at a similar intensity on land.

Keywords: water-based exercise, post-exercise hypotension, blood pressure, cardiovascular response, normotensive women

\section{Introduction}

Physical activity is currently considered to be a nonpharmacological strategy for treatment of hypertension. ${ }^{1}$ Among the effects of physical activity on the cardiovascular system, post-exercise hypotension $(\mathrm{PEH})$ has been studied in hypertensive subjects with clinically relevant implications. ${ }^{2,3}$

Aerobic exercise is recommended in most guidelines for hypertension control. ${ }^{1,4}$ At present, water-based exercise is considered a popular aerobic activity, ${ }^{5}$ and numerous benefits are found, including decreased contact force and stress on weight-bearing joints, bones, and muscles, which reduces pain. ${ }^{6}$ These activities have been used in 
rehabilitative, therapeutic, and general conditioning programs, and are thought to be particularly useful for people with lower extremity injuries. For this reason, water-based exercises are considered to be suitable for individuals with weight-bearing problems and those of middle or advanced age., ${ }^{7,8}$

Several physiological adaptations occur with water-based exercise, including a greater reduction in sympathetic drive, reduced catecholamine release, reduction of peripheral vascular resistance, and suppression of the vasopressin and reninangiotensin systems than those observed with land exercise. ${ }^{9-13}$ However, few studies have investigated the $\mathrm{PEH}$ response after water-based exercise. ${ }^{14}$ Thus, the aim of this study was to evaluate the effect of water-walking on the $\mathrm{PEH}$ response in healthy trained and untrained women. Additionally, the effectiveness of an acute water-walking session was compared with that of an acute session of land-walking.

\section{Materials and methods Subjects}

Twenty-three normotensive women without any physical limitations participated in this study. The women were allocated to one of two groups, ie, trained $(n=11)$ or untrained $(n=12)$ in water-based exercise. To be included in the trained group, women had to have participated for a minimum of 12 months in a regular water-based exercise program and those who had not participated in any exercise program before the study were assigned to the untrained group. All procedures followed the principles of the Declaration of Helsinki (www.wma.net/e/policy/b3.htm). This research was approved by the ethics committee of the Federal University of São Paulo. Exclusion criteria were recent hospitalization, symptomatic cardiorespiratory disease or cardiac alterations, hypertension or metabolic syndrome, severe renal or hepatic disease, cognitive impairment, a progressive or debilitating condition, marked obesity with inability to exercise, and any other medical contraindication to physical exercise.

\section{Acute exercise session}

Initially the subjects performed an incremental treadmill exhaustion test according to Balke's protocol. ${ }^{15}$ The $\mathrm{VO}_{2}$ values were recorded every 30 seconds using a gas analyzer (Quinton QMC 000350, Bothell, WA). The parameters used to determine peak $\mathrm{VO}_{2}$ were respiratory exchange ratio $>1.1$ and maximum heart rate less than 10 beats per minute (bpm) of the age-predicted value. Heart rate was monitored every 30 seconds during the test by 12-lead electrocardiography (Quinton, Q710 Bothell, WA). Seven days after peak $\mathrm{VO}_{2}$ determination, the subjects returned to the laboratory to perform the first walking session at $40 \%$ of peak $\mathrm{VO}_{2}$ for 45 minutes. Following the test, no differences were found between heart rate corresponding to exercise intensity for the different forms of exercise on land-walking (untrained $120 \pm 4 \mathrm{bpm}$, trained $115 \pm 3 \mathrm{bpm}$ ) and on water-walking (untrained $121 \pm 3 \mathrm{bpm}$, trained $117 \pm 4 \mathrm{bpm}$ ).

Subjects who started with land-walking returned to the laboratory seven days later to perform water-walking. Before the exercise session, subjects remained seated for 20 minutes, during which blood pressure and heart rate were measured. After the exercise session, blood pressure and heart rate were remeasured at 15,30, 45, and 60 minutes with subjects seated. Due to the physical properties of water, whereby resistance increases with velocity of movement, exercise intensity was monitored in all participants by heart rate (Accurex Plus, Polar Electro, Kempele, Finland) and subjective level of exertion on the Borg scale as confirmed in previous publications. ${ }^{16-18}$ The same parameters were measured for land-walking exercise. The subjects were instructed to move through the full range of motion, without exceeding the exercise intensity stipulated.

\section{Body composition}

Biometric parameters were assessed according to the method described by Serra et al. ${ }^{19}$ Height was measured to the nearest $0.1 \mathrm{~cm}$ using a Cardiomed stadiometer. Body mass was measured to the nearest $0.1 \mathrm{~kg}$ using a Filizola scale (Personal Line 150 model). Body mass index $\left(\mathrm{kg} / \mathrm{m}^{2}\right)$ was calculated as body mass/height $\times$ height.

\section{Blood pressure and heart rate}

Subjects arrived in the laboratory at around 8-10 am and remained resting in a seated position for 20 minutes before initiation of exercise. Blood pressure was measured by auscultation (sphygmomanometer and stethoscope, Becton Dickinson, Franklin Lakes, NJ) as described elsewhere, ${ }^{20}$ and the average of three measurements was considered representative for each subject. The subjects did not perform any physical activity for at least 24 hours before evaluation and did not take any caffeine or alcohol. All measurements were performed by one experienced researcher.

To assess the influence of water immersion on heart rate and blood pressure, all subjects were immersed in water and then remained standing for 60 minutes (control session). Measurements were performed every 5 minutes and the water temperature was adjusted to $30^{\circ} \mathrm{C} \pm 1^{\circ} \mathrm{C}$. Water depth was maintained at the xiphoid process for the study period.

All measurements were performed in a seating position before (baseline) and 15, 30, 45, and 60 minutes after both types 
of exercise session. Heart rate was continuously measured and recorded on a beat-by-beat basis using Polar Electro equipment during exercise and following exercise bouts.

\section{Statistical analysis}

Data are presented as means \pm standard deviation and were analyzed using SigmaStat 3.5 (www.Systat.com). The ShapiroWilk test was applied to evaluate normal distribution of the data, and Levene's test was used to verify the homogeneity of variances. Student's $t$-test was used as appropriate and repeatedmeasures analysis of variance was used to determine the degree of difference in blood pressure between resting values and 15 , 30, 45, and 60 minutes following exercise. Newman-Keuls post hoc test was used to determine differences. A value of $P \leq 0.05$ was accepted as being statistically significant.

\section{Results}

There were no significant differences between the groups for age, height, and weight (Table 1). However, the maximum aerobic power of the trained group was significantly higher than that of the untrained group (Table 1). The influence of the exercise environment on blood pressure levels is shown in Figure 1. No significant differences were found for systolic blood pressure between exercise performed on land and on water immersion (land, $108 \pm 8 \mathrm{mmHg}$; water, $102 \pm 3 \mathrm{mmHg} ; P>0.05$ ), diastolic blood pressure (land, $69 \pm 6 \mathrm{mmHg}$; water, $60 \pm 3 \mathrm{mmHg}$; $P>0.05$ ) and mean arterial pressure (land, $82 \pm 6 \mathrm{mmHg}$; water, $74 \pm 3 \mathrm{mmHg} ; P>0.05)$ in the untrained group. Similar results were found in the trained group, for which blood pressure levels were not statistically different according to training environment. No differences was found in heart rate between land-walking and water-walking for untrained women (73 $\pm 4 \mathrm{bpm}$ and $66 \pm 3 \mathrm{bpm}$, respectively) or trained women (62 $\pm 24 \mathrm{bpm}$ and $58 \pm 5 \mathrm{bpm}$ ), but there was differences between the groups for land parameters, as shown in Figure 1D.

Figure 2 shows the systolic and diastolic blood pressure and mean arterial pressure results in untrained and trained women performing water-walking and land-walking at $40 \%$ of peak $\mathrm{VO}_{2}$. There was a decrease $(P<0.05)$

Table I Demographic characteristics of patients

\begin{tabular}{lccc}
\hline & Untrained & Trained & P value \\
\hline Age (years) & $33 \pm 7$ & $32 \pm 6$ & $>0.05$ \\
Body weight $(\mathrm{kg})$ & $57 \pm 16$ & $63 \pm 8$ & $>0.05$ \\
Height $(\mathrm{cm})$ & $162 \pm \mathrm{II}$ & $167 \pm 13$ & $>0.05$ \\
Body mass index $\left(\mathrm{kg} / \mathrm{m}^{2}\right)$ & $22 \pm 7$ & $23 \pm 3$ & $>0.05$ \\
$\mathrm{VO}_{2 \max }(\mathrm{mL} / \mathrm{kg} / \mathrm{min})$ & $31 \pm 3$ & $45 \pm 8$ & $<0.01$ \\
\hline
\end{tabular}

Note: Values expressed as means \pm standard deviation. Abbreviation: $\mathrm{VO}_{2 \max }$, maximum aerobic power. in systolic blood pressure after $30(99 \pm 4 \mathrm{mmHg})$, $45(98 \pm 2 \mathrm{mmHg})$, and $60(97 \pm 3 \mathrm{mmHg})$ minutes compared with resting conditions $(108 \pm 8 \mathrm{mmHg})$. There was no significant decrease in systolic blood pressure after land-walking (Figures 1A and B). When trained women executed water-walking, systolic blood pressure decreased $(P<0.05)$ after $15(102 \pm 6 \mathrm{mmHg}), 30(101 \pm 7 \mathrm{mmHg})$, 45 (101 $\pm 6 \mathrm{mmHg})$, and 60 minutes $(100 \pm 9 \mathrm{mmHg}) \mathrm{com}-$ pared with resting conditions $(111 \pm 9 \mathrm{mmHg})$. On the other hand, systolic blood pressure decreased $(P<0.05)$ only after 45 (99 $\pm 7 \mathrm{mmHg})$ and $60(97 \pm 6 \mathrm{mmHg})$ minutes compared with rest $(107 \pm 5 \mathrm{mmHg})$ after land-walking. The untrained group showed a significant reduction $(P<0.05)$ in diastolic blood pressure at $45(64 \pm 6 \mathrm{mmHg})$ and 60 $(62 \pm 5.0 \mathrm{mmHg}$ ) minutes after water-walking as compared with rest $(69 \pm 5 \mathrm{mmHg})$. No modifications in diastolic blood pressure were observed after land-walking. In the trained group, diastolic blood pressure showed a decrease $(P<0.05)$ only until 60 minutes after land-walking $(63 \pm 4 \mathrm{mmHg})$ compared with rest $(67 \pm 6 \mathrm{mmHg})$. Mean arterial pressure decreased $(P<0.05)$ only at 60 minutes $(82 \pm 6 \mathrm{mmHg}$ at rest vs $74 \pm 4 \mathrm{mmHg}$ ) after water-walking in untrained women.

\section{Discussion}

Utilization of several aerobic exercise modalities, such as walking, running, cycling, and swimming, as a nonpharmacological therapy for hypertension is well documented. ${ }^{21-23}$ However, the effects of water-based exercise are not completely understood. To our knowledge, there is no study showing the hypotensive effect of water-walking vs landwalking in normotensive trained and untrained individuals.

Assuming that PEH is a consequence of several changes that occur during exercise, and that during water-walking, the cardiovascular adjustments are different from those occurring during land-walking, the objective of this study was to evaluate the $\mathrm{PEH}$ in response to different exercise environments. Thus, we demonstrated that blood pressure was strongly affected by the water-walking exercise in untrained and trained normotensive individuals. This finding is in agreement with previous studies obtained for land-walking exercise. ${ }^{24-29}$ The absence of blood pressure modifications in the control water immersion states indicates that the decrease in blood pressure was induced by exercise.

The main finding in this study was the anticipated decrease in blood pressure in untrained women after a water exercise session compared with land exercise. Our results are in accordance with previous studies, which found a decrease of 6-10 $\mathrm{mmHg}$ in systolic blood pressure and $2-5 \mathrm{mmHg}$ in 
A

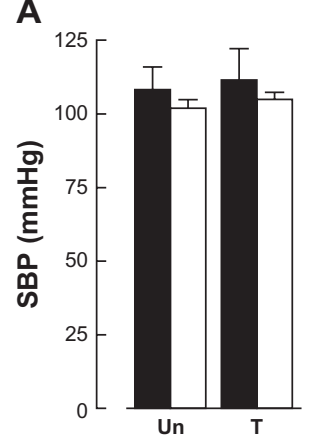

B

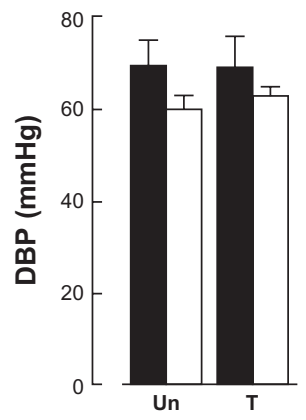

C

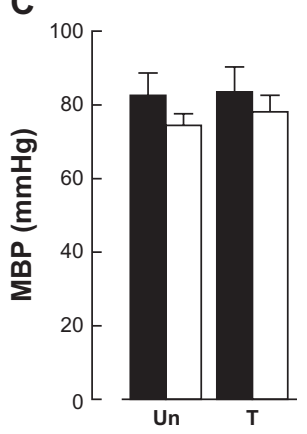

D

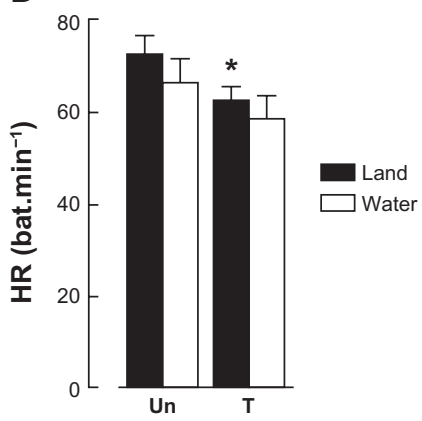

Figure I Values expressed as means \pm standard deviation. Panel (A) systolic blood pressure, (B) diastolic blood pressure, (C) mean arterial pressure, and (D) heart rate. Note: *Significantly different $(P<0.05)$ vs untrained on land.

diastolic blood pressure in normotensive untrained individuals performing aerobic exercise on land. ${ }^{28,30-32}$ These results obtained in a water-walking condition could be related to greater reduction in sympathetic activity, reduced catecholamine release, reduction of peripheral vascular resistance, and suppression of the vasopressin and renin-angiotensin systems than that seen for land-based exercise..$^{10,34,35}$ Unfortunately, in the present study, these parameters were not measured and this is a limitation of our research.

The present study extends the clinical relevance of PEH in a water environment, indicating that an aquatic environment may be used as a relevant tool for physical exercise in hypertensive individuals. Thus, water-walking exercise as a nonpharmacological therapy can contribute to control of blood pressure, prevention of hypertension, and recovery of cardiovascular function. The exercise performed in a head-out waterimmersion condition was capable of producing PEH. These data are in agreement with a study by Meyer and Bücking, ${ }^{13}$ who reported that immersion up to the iliac crest was not enough to produce hemodynamic changes. It is possible that the initial depth required to promote significant changes in PEH may be the height of the xiphoid process. This phenomenon had been observed in previous research by our group, ${ }^{14}$ in which aerobic exercise on land and in water (immersion up to the waist) performed by hypertensive individuals at $50 \%$ of peak $\mathrm{VO}_{2}$ was not capable of inducing significant hemodynamic changes. Furthermore, the absence of PEH on land-walking exercise in sedentary women reinforces the idea that the environment can be a determining factor for hypotension.

In trained women, PEH was more evident at 15, 30, 45, and 60 minutes after water-walking. For land exercise, the drop in systolic blood pressure occurred only after 45 and 60 minutes. Additionally, there was no difference between trained and sedentary individuals. These results are in accordance with other studies, in which the authors found no differences in the magnitude of hypotension between trained and sedentary individuals. ${ }^{34,36}$ Some studies have shown that aerobic exercise at a higher intensity produces greater $^{3,27,34}$ and more lasting ${ }^{3,27} \mathrm{PEH}$ as compared with moderate intensity aerobic exercise. In fact, we can also relate this result to the low intensity of aerobic exercise ( $40 \%$ of peak $\mathrm{VO}_{2}$ ), that may not have been enough to induce a significant drop in blood pressure in the trained group.

Some limitations to our research should be mentioned. The mechanisms of hypotension were not investigated in the present study, but previous studies have shown that hypotension can be provoked by a reduction in peripheral vascular resistance, ${ }^{36}$ sympathetic activity, ${ }^{37}$ and a lower systolic volume, ${ }^{37}$ and that these physiological responses can be amplified by exercise performed in water. ${ }^{11,14}$ However, it is important to mention that more research involving hypertensive subjects of both gender are necessary to confirm this hypothesis. According to Halliwill, ${ }^{38}$ there is a sustained vasodilatation after exercise induced by neural and vascular components, which is associated with a decrease in the vasoconstrictor effect of catecholamines. The neural component is related to a decrease in the sympathetic activity of the muscle (that would involve the readjustment of the baroreflex). The vascular component is associated with an attenuation of sensitivity to sympathetic stimuli (with a lower vascular response to activation of alpha-adrenergic receptors), as well as by the effect of vasodilator substances.

Finally, our data have a clinically relevant role, in light of the comments by Forjaz et $\mathrm{al}^{3}$ that blood pressure values at 24 hours after an exercise session remained at lower levels than the pressure values of 24 hours after a day without exercise. In summary, exercise performed in a water environment can be an efficient and safe therapeutic approach to controlling blood pressure. Furthermore, numerous benefits could be found for water-based exercise (decreased contact force and stress on weight-bearing joints, bones, and muscles, 

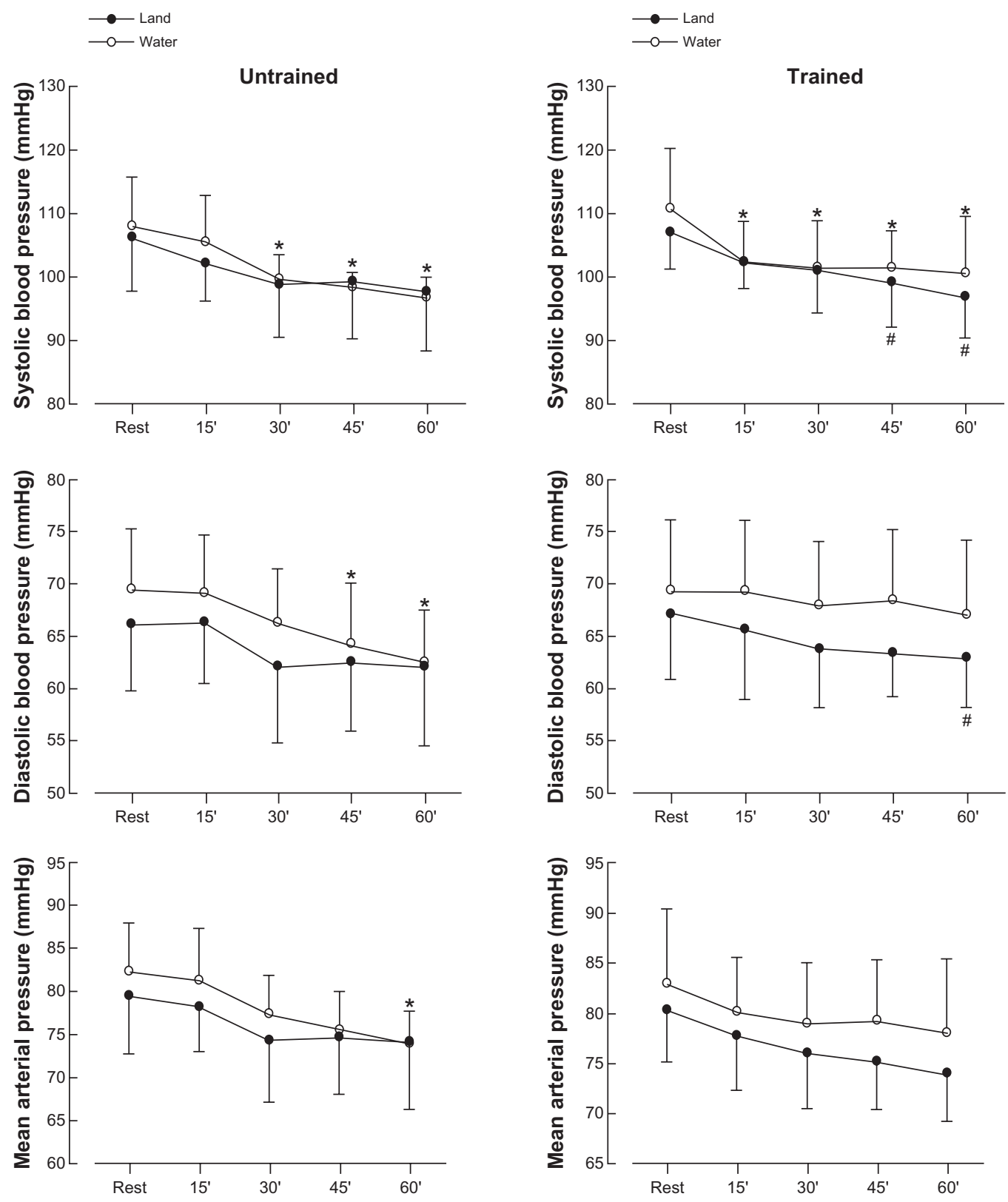

Figure 2 Values are expressed as means \pm standard deviation of systolic, diastolic, and mean blood pressure in untrained and trained women measured after an acute session of exercise in water $(\mathrm{O})$ and on land $(\bullet)$.

Notes: *Significantly different $(P<0.05)$ vs rest in water; ${ }^{*}$ significantly different $(P<0.05)$ vs rest on land.

which reduces pain), and obese hypertensive individuals may enjoy this activity safely.

In the current study, group comparisons (eg, untrained and trained women) were not made, so differences between water-based and land-based exercise in terms of effect on PEH were not tested according to training status. Clearly, this is a logical next step in trying to understand how differences in PEH occur as well as assess this response in hypertensive subjects.

The present study demonstrated that acute sessions of water-walking and land-walking induced important PEH.
Additionally, walking performed in chest-deep water was more effective than walking at a similar intensity on land in inducing PEH in untrained healthy women.

\section{Disclosure}

The authors report no conflicts of interest in this work.

\section{References}

1. Pescatello LS, Franklin BA, Fagard R, Farquhar WB, Kelley GA, Ray CA. American College of Sports Medicine. American College of Sports Medicine position stand: exercise and hypertension. Med Sci Sports Exerc. 2004;35:533-553. 
2. Forjaz CL, Santaella DF, Rezende LO, Barretto AC, Negrão CE. Effect of exercise duration on the magnitude and duration of post-exercise hypotension. Arq Bras Cardiol. 1998;70:99-104. Portuguese.

3. Forjaz CL, Cardoso CG Jr, Rezk CC, Santaella DF, Tinucci T. Post-exercise hypotension and hemodynamics: the role of exercise intensity. J Sports Med Phys Fitness. 2004;44:54-62.

4. [VI Brazilian Guidelines on Hypertension]. Arq Bras Cardiol. 2010; 95(1 Suppl):1-51. Portuguese.

5. Fernhall B, Manfredi TG, Congdon K. Prescribing water-based exercise from treadmill and arm ergometry in cardiac patients. Med Sci Sports Exerc. 1992;24:139-143.

6. Bartels EM, Lund H, Hagen KB, Dagfinrud H, Christensen R, Danneskiold-Samsøe B. Aquatic exercise for the treatment of knee and hip osteoarthritis. Cochrane Database Syst Rev. 2007;17:CD005523.

7. Bocalini DS, Serra AJ, Murad N, Levy RF. Water- versus land-based exercise effects on physical fitness in older women. Geriatr Gerontol Int. 2008;8:265-271.

8. Bocalini DS, Serra AJ, Rica RL, Santos LD. Repercussions of training and detraining by water-based exercise on functional fitness and quality of life: a short-term follow-up in healthy older women. Clinics (Sao Paulo). 2010;65:1305-1309.

9. Lin YC. Circulatory functions during immersion and breath-hold dives in humans. Undersea Biomed Res. 1984;11:123-138.

10. Epstein M. Renal effects of head-out water immersion in humans: a 15-year update. Physiol Rev. 1992;72:563-621.

11. Gabrielsen A, Warberg J, Christensen NJ, et al. Arterial pulse pressure and vasopressin release during graded water immersion in humans. Am J Physiol. 2000;278:R1583-1588.

12. Reilly TR, Dowzer NC, Cable NT. The physiology of deep-water running. J Sports Sci. 2003;21:959-972.

13. Meyer K, Bücking J. Exercise in heart failure: should aqua therapy and swimming be allowed? Med Sci Sports Exerc. 2004;36:2017-2023.

14. Pontes FL Jr, Bacurau RF, Moraes MR, et al. Kallikrein kinin system activation in post-exercise hypotension in water running of hypertensive volunteers. Int Immunopharmacol. 2008;8:261-266.

15. Balke B, Ware R. An experimental study of physical fitness of air force personnel. U S Armed Forces Med J. 1959;10:675-688.

16. Borg GA. Psychophysical bases of perceived exertion. Med Sci Sports Exerc. 1982;14:377-381.

17. Takeshima N, Nakata M, Kobayashi F, et al. Oxygen uptake and heart rate differences between walking on land and in water in the elderly. J Aging Phys Activity. 1997;5:126-134.

18. American College of Sports Medicine. The recommended quantity and quality of exercise for developing and maintaining cardiorespiratory and muscular fitness, and flexibility in healthy adults. Med Sci Sports Exerc. 1998;30:975-991.

19. Serra AJ, do Amaral AM, Rica RL, et al. [Determination of body density by generalized equations: easiness and simplification in the method]. ConScientiae Saúde. 2009;8:19-24. Portuguese.

20. Pickering TG, Hall JE, Appel LJ, et al. Recommendations for blood pressure measurement in humans and experimental animals: part 1. Blood pressure measurement in humans: a statement for professionals from the subcommittee of professional and public education of the American Heart Association Council on High Blood Pressure Research. Hypertension. 2005;45:142-161.
21. Tanaka H, Bassett DR, Howley ET, Thompson DL, Ashraf M, Rawson FL. Swimming training lowers the resting blood pressure in individuals with hypertension. J Hypertens. 1997;15:651-657.

22. Floras JS, Notarius CF, Harvey PJ. Exercise training - not a class effect: blood pressure more buoyant after swimming than walking. J Hypertens. 2006;24:269-272.

23. Cider A, Sveälv BG, Täng MS, Schaufelberger M, Andersson B. Immersion in warm water induces improvement in cardiac function in patients with chronic heart failure. Eur J Heart Fail. 2006;8:308-313.

24. Fitzgerald W. Labile hypertension and jogging: new diagnostic tool or spurious discovery? BMJ. 1981;282:542-544.

25. Piepoli M, Isea JE, Pannarale G, Adamopoulos S, Sleight P, Coats AJ. Load dependence of changes in forearm and peripheral vascular resistance after acute leg exercise in man. J Physiol. 1994;478:357-362.

26. Forjaz CL, Tinucci T, Ortega KC, Santaella DF, Mion D Jr, Negrão CE. Factors affecting post-exercise hypotension in normotensive and hypertensive humans. Blood Press Monit. 2000;5:255-262.

27. MacDonald JR, Rosenfeld JM, Tarnopolsky MA, Hogben CD, Ballantyne CS, MacDougall JD. Post exercise hypotension is not mediated by the serotonergic system in borderline hypertensive individuals. J Hum Hypertens. 2002;16:33-39.

28. McCord JL, Halliwill JR. $\mathrm{H}_{1}$ and $\mathrm{H}_{2}$ receptors mediate postexercise hyperemia in sedentary and endurance exercise-trained men and women. J Appl Physiol. 2006;101:1693-1701.

29. Guidry MA, Blanchard BE, Thompson PD, et al. The influence of short and long duration on the blood pressure response to an acute bout of dynamic exercise. Am Heart J. 2006;151:1322. e5-e12.

30. Senitko AN, Charkoudian N, Halliwill JR. Influence of endurance exercise training status and gender on postexercise hypotension. $J \mathrm{Appl}$ Physiol. 2002;92:2368-2374.

31. Harvey PJ, Morris BL, Kubo T, et al. Hemodynamic after-effects of acute dynamic exercise in sedentary normotensive postmenopausal women. J Hypertens. 2005;23:285-292.

32. Morães MR, Bacurau RF, Ramalho JD, et al. Increase in kinins on postexercise hypotension in normotensive and hypertensive volunteers. Biol Chem. 2007;388:533-540.

33. Dujic Z, Ivancev V, Valic Z, et al. Post-exercise hypotension in moderately trained athletes after maximal exercise. Med Sci Sports Exerc. 2006;38:318-322

34. Jones H, George K, Edwards B, Atkinson G. Is the magnitude of acute post-exercise hypotension mediated by exercise intensity or total work done? Eur J Appl Physiol. 2007;102:33-40.

35. Brownley KA, Hinderliter SG, West SS, et al. Sympathoadrenergic mechanisms in reduced hemodynamic stress responses after exercise. Med Sci Sports Exerc. 2003;35:978-986.

36. Kulics JM, Collins HL, DiCarlo SE. Post-exercise hypotension is mediated by reductions in sympathetic nerve activity. Am J Physiol. 1999; 276:H2-H3.

37. Brandão Rondon MU, Alves MJ, Braga AM, et al. Postexercise blood pressure reduction in elderly hypertensive patients. $\mathrm{J} \mathrm{Am} \mathrm{Coll} \mathrm{Cardiol.}$ 2002;39:676-682.

38. Halliwill JR. Mechanisms and clinical implications of post-exercise hypotension in humans. Exerc Sport Sci Rev. 2001;29:65-70.
International Journal of General Medicine

\section{Publish your work in this journal}

The International Journal of General Medicine is an international, peer-reviewed open-access journal that focuses on general and internal medicine, pathogenesis, epidemiology, diagnosis, monitoring and treatment protocols. The journal is characterized by the rapid reporting of reviews, original research and clinical studies across all disease areas.
A key focus is the elucidation of disease processes and management protocols resulting in improved outcomes for the patient. The manuscript management system is completely online and includes a very quick and fair peer-review system. Visit http://www.dovepress.com/ testimonials.php to read real quotes from published authors. 